\title{
Establishing a Method to Support Academic and Professional \\ Competence throughout an Undergraduate Radiography Programme
}

\begin{abstract}
Purpose

Radiography degree programmes are coming under increasing pressure from the community to ensure that graduates have not only the necessary academic development but also the practice-based skills. This study aims to establish a method of monitoring students’ progress towards, and ability to meet, academic and professional competences throughout a radiography programme.
\end{abstract}

\section{Methods}

Questionnaires were designed for students and academic staff to determine the stages and standards of progress of competence development, and to inform the review process of the current assessment tools throughout the programme. A literature search identified the appropriate pedagogy as a basis for devising the method. Another questionnaire was distributed to overseas radiography institutions to gain insights into other assessment practices to validate the framework.

\section{Results \& Discussion}

It was established that years of study rather than semester periods were appropriate to allow students to meet the standards. Discrepancies were noted in the expectations between academic staff (higher expectations) and students (more realistic) in terms of the 
pace of development expected. As students progress at different rates, and do not experience the same clinical exposure, their ability to meet expectations may differ and so both sets of expectations were combined as a range of criteria. A multi-dimensional assessment approach should be adequate to gauge students’ progress but time and resource effectiveness has not yet been addressed. The portfolio was identified as the pedagogy capable of integrating all the competence assessment tools, linked by reflective writing, to gather individual outcomes into a whole, and form a holistic framework.

\section{Outcome}

The portfolio framework will initially run as a voluntary activity and standards of progress corresponding to the students' stages will be delivered to participants in advance. Participants will be required to select materials and reflect on these, as evidence of development. Faculty members will provide support and feedback to students and oversee the whole process.

\section{Keywords}

\section{Competence}

Portfolio

Assessment

Radiography Programme

CPD

PACS 


\section{Introduction}

Radiography degree programmes, as with other health care undergraduate programmes worldwide, are coming under increasing pressure from the community to ensure that graduates have not only the necessary academic development but also the practice-based skills required by their registering authorities and employers. ${ }^{1}$ Also, the changing health care environment is driving the need for expanded roles and responsibilities of practitioners. This highlights the importance of professional educational reform to meet these challenges. ${ }^{2-4}$ The notions of 'fitness for practice', 'fitness for purpose' and 'fitness for award' have emerged in the United Kingdom (UK) as the benchmark standards for practitioners, and also as the requirements of professional educational programmes such as undergraduate degree courses. ${ }^{1-3,5-10}$ However, an emphasis on one of these without regard for the other components, is often over emphasized by the corresponding parties. For example, academic institutions tend to emphasize the value of 'fitness for award' rather than the importance of 'fitness for practice' and 'fitness for purpose'. $3,9,10$ Consequently, the programme may not provide the appropriate solutions to address issues such as inadequate practical skills of graduates of a degree programme. The concept of competence, as noted in the United States of America (USA), could be considered a more appropriate protocol for programme development, to ensure that graduates are measured in terms of both academic excellence and professional competence, ensuring relevance to all stakeholders, including registering authorities, employers and educational institutions. ${ }^{3,4,9,10}$ Furthermore, caution should be taken to ensure that the outcomes-based competence approach to education is incorporated into learning objectives, aiming towards academic excellence. These are inherent characteristics of a university education, and it is important that degree programmes, because of the workplace demand for improved practice skills, are not transformed back to diploma-type programmes, thereby ignoring academic development which requires, for example, powers of analysis and critique. $^{3}$

Programme redevelopment for the Bachelor of Science (Honours) in Radiography, at The Hong Kong Polytechnic University (PolyU), has been based on the application of Biggs'

${ }^{11}$ constructive alignment theory. Constructive alignment refers to the establishment of learning objectives / intended learning outcomes with appropriate cognitive demands for students relevant to the context. Basically, all subjects within the curriculum have been re-designed so that the intended learning outcomes, learning and teaching activities (LTAs), and assessment methods are clearly stated and aligned so that they complement one another. The teaching methods and assessments need to be appropriate to facilitate students in meeting the intended learning outcomes and to assess whether, in fact, they achieve them. The requirements of the redevelopment were informed by the results of the Radiography Applied Learning Project, a project funded by the University Grants Committee of Hong Kong (HK). This project aimed to establish the standards of practice required for graduate radiographers in HK. It ascertained radiography graduating competences through a series of interviews and a questionnaire survey involving academics, clinicians of different grades and recent graduates. Members of the Hong Kong Radiographers Board, the professional registration body, participated in the study, 
though not in their capacity as Board members. The reform process necessitated the integration of competence requirements for radiographers with the intended learning outcomes for each subject and the programme overall. In this way, constructive alignment was achieved. The whole process is seen as facilitating students' attainment of the required graduating professional competences.

It was intended that graduates exiting the Radiography programme would attain both the academic excellence and professional competence levels expected by all stakeholders. However, pitfalls may still exist, such as an inability to note the actual degree of attainment of graduating professional competence requirements at graduation. Currently, one can only identify whether graduates have fulfilled the basic requirements and it is difficult for graduates to note their own progress towards the attainment of competence requirements. Therefore, it is useful to establish a framework to capture learning outcomes that indicate students' progress in identified areas of competence, leading on towards meeting identified professional graduating competences, and as a way to ensure the validity of the redevelopment.

\section{Aim}

The aim of this study is to establish a method of monitoring Radiography students' progress towards, and ability to meet, graduating professional competences.

\section{Objectives}

The objectives of the study are to:

1. identify programme learning outcomes that provide evidence of professional development, including:

(a) the development of academic, personal and professional attributes for life long learning and clinical practice, and;

(b) the integration of theory and practice

2. develop a framework that provides proper monitoring and feedback on progress of professional development throughout the programme, leading to attainment of graduate professional competences

\section{Methods}

Quantitative and qualitative research approaches were used and the data collection methods included questionnaires and secondary data. Initial questionnaires were designed to identify programme learning outcomes that provided evidence of professional development based on the perceptions of radiography academics, that is subject leaders in the B.Sc. (Hons) Radiography programme, and third (final) year students within the programme. The purpose was to determine both the stages and standards of progress of competence development, and to inform the review process of the current assessment tools throughout the programme. This provided the essential ingredients to devise a framework (method) to inform students of the requirements of competence development 
and their own progress of development at different stages. Stages of progress refer to the periods of time required for students to develop the competences from a lower to a higher level, while standards of progress define the summated effects of all subjects within the radiography curriculum at a particular stage. The basic unit of the Radiography programme involves a subject, which usually lasts for one fourteen week semester, with a total of six semesters over a three year period.

The staff and student questionnaires were similar, having been developed based on secondary data, such as radiography graduating competences and programme documents from the B.Sc. (Hons) Radiography for the academic year 2004/05. The first question was multifaceted and required respondents to indicate the level of development (foundation, applied, graduate or NA) that students should achieve for a range of competences, that is statements of radiography graduating competences, once they had completed a particular subject (Table 1), or at the completion of a semester or a period of clinical placement for Clinical Studies (Table 2), using a four point scale as follows:

1. Foundation --- provides an introduction for further learning towards the graduate competence

2. Applied --- establishes an applied understanding in this subject / stage / clinical study

3. Graduate --- provides the abilities and understanding to meet the required graduate competence

4. This subject / stage / clinical study does not contribute towards meeting this competence (NA)

This question served two purposes. The first was to identify what competence development, from the list of one hundred and eight competences, would be included in the outcomes of a particular subject / each semester / clinical placement. The second was to determine the level of development for the selected competences, as competence development is not an 'all or none' process, but rather a continuum of development, similar to Benner's ${ }^{12}$ novice to expert theory. ${ }^{9}$ Therefore, the scale, 'foundation, applied and graduate,' was developed to acknowledge the contribution of each subject / stage / clinical placement period, especially those in the first and second years that supported the development towards required graduate competences, but did not account for a complete development.

An additional follow-up question was included in the staff questionnaire asking subject leaders to categorize the identified competences into three types, that is psychomotor, cognitive or affective holistic competences. Depending on the LTAs in place, a particular subject may not be capable of providing opportunities for students to develop the three domains of an identified single competence. This question was useful in defining the expectations of competence development more finely. Mainly, however, it was to inform the review process of current assessment tools in every subject, so as to ensure that appropriate assessment tools were in place for monitoring students' progress. The descriptions of psychomotor, cognitive and affective domains, as stated in the questionnaire, are: 
A. Psychomotor --- the ability to 'do' the procedures and tasks which are fundamental to completing learning requirements

B. Cognitive --- understanding of theory / knowledge as demonstrated in the ability to apply it appropriately into specific situations

C. Affective --- the attitude demonstrated in the professional context and which embodies the concept of practising within an ethically appropriate framework ${ }^{13}$ (Table 1)

Table 1. A snapshot of the staff questionnaire

\section{Social responsibilities and ethical practice}

\section{Ensures at all times radiographers rights:}

1. Can say 'no' to inappropriate requests

2. Can explain reasons for decision

3. Can discuss pros and cons of disputed situations

Column A
\begin{tabular}{|l|l|l|l|}
\hline 1 & 2 & 3 & 4 \\
\hline & & & \\
\hline & & & \\
\hline & & & \\
\hline
\end{tabular}

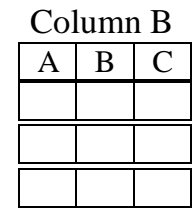

* For column A, you are expected to tick $(\sqrt{ })$ ONLY ONE box for each competence and can tick $(\sqrt{ })$ MORE THAN ONE aspect if appropriate in column B. Codes 1-4 under column A represent levels of development from foundation to NA and Codes A-C under column B stand for psychomotor, cognitive or affective respectively.

Table 2. A snapshot of the student questionnaire

\section{Social responsibilities and ethical practice}

Ensures at all times radiographers rights:

1. Can say 'no' to inappropriate requests

2. Can explain reasons for decision

3. Can discuss pros and cons of disputed situations

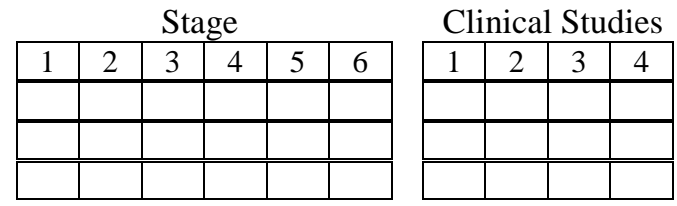

* You are expected to rate on each stage and for clinical studies for each competence by writing the code $(1,2,3$ or 4$)$ inside the boxes. Codes 1-4 represent levels of development from foundation to NA respectively.

A literature search was conducted to identify an appropriate pedagogy to provide proper monitoring and feedback on the progress of professional development throughout the programme. This was supplemented by information from the Hospital Authority (HK) (2002): Assessment on Clinical Training for Graduate Radiographers in the Hong Kong Hospital Authority. A further questionnaire was distributed to programme leaders, or their delegates, at overseas radiography institutions in the UK, Australia (Aus) and New Zealand (NZ), to gain insights into assessment practices for other programmes, so as to help validate the framework as it emerged. It should be noted the B.Sc. (Hons) Radiography programme is unique in $\mathrm{HK}$ as PolyU is the sole provider of undergraduate radiography education.

\section{Data Analysis}


The determination of the stages and standards of progress was mainly based on the use of contingency tables and chi-square tests. A contingency table, providing descriptive statistics, was used to establish the relationship between expected levels of competence development (in terms of the proportions of competence statements with 'NA', 'Foundation', 'Applied' and 'Graduate' ratings) across semesters and years, so as to establish the stage of progress applicable. A synthesized category, that is overall expected competence development of the radiography programme (whole programme), was also established. The purpose of this category was to ensure that the Radiography programme could support graduating students to meet all the established graduating competence requirements. Chi-square test was then applied to the contingency table to determine the statistical significance of any disproportion noted in the table. During the construction of the contingency tables, the rating of each competence statement was required. For the staff questionnaire, the data for each subject were grouped under the categories of either semester $(1,2,3,4,5$ or 6$)$ or year $(1,2$ or 3$)$ as well as for the whole programme. The highest rating for subjects in the same category, for a particular competence statement, was noted as the rating for that competence. For the student questionnaire, the median was used to determine the central tendency of expected competence development, that is ratings of competence statements for each semester. Similar to the staff questionnaire, the data for each semester were then grouped under the categories, year $(1,2$ or 3$)$ as well as for the whole programme, so as to determine the ratings of individual competence statements for each year. Hence, the standards of progress were developed, which were the ratings of competence statements for either each semester or year, depending on the determined stage of progress.

For the overseas assessment practices, descriptive statistics, such as the proportion of choices, were applied to the closed questions. Content analysis, which is the analysis of themes and patterns which had emerged, was used for the open questions with quasistatistics as an accounting system. Validity of the questionnaires was assured via a pilot study, with the corresponding target participants. ${ }^{14,15}$

\section{Results}

\section{Response Rates}

Thirty-eight staff questionnaires were sent to the corresponding subject leaders and twenty-eight returned for a response rate of $73.68 \%$. It should be noted that staff members were required to complete a questionnaire for each of the subjects they were leading. There were thirty-two third year students in the 2004-05 academic year. The student questionnaire was distributed to them during the last tutorial of a professional subject in the second semester. Twenty-eight questionnaires were collected, yielding a response rate of $87.5 \%$. Thirty-five questionnaires were sent via e-mail to overseas institutions (twenty-four for the UK, eight for Aus. and three for NZ). Ten questionnaires were returned, yielding an overall response rate of 28.6\%. The individual response rates from the UK, Aus. and NZ were 25\% (6 out of 24), 37.5\% (3 out of 8) and 33.3\% (1 out of 3) respectively. 


\section{Staff and Student Questionnaires}

Four contingency tables were constructed based on the data from the staff and student questionnaires, so as to determine the stages of progress and also to provide some insight into the standards of progress. Among the one hundred and eight radiography graduating competence statements, seventeen related to elective subjects and hence were excluded from the construction of contingency tables. Since each student could only take two modules from seven elective options, these expectations should only be posed to the corresponding students. Two cross-tabulations were constructed to present the relationship between expected levels of competence development and semesters, based on the staff (Table 3) and student (Table 4) data. Another two cross-tabulations (Table 5, staff and Table 6, students) are used to illustrate findings across years.

Table 3. Relationship between expected levels of competence development and semesters, based on staff data

\begin{tabular}{|c|c|c|c|c|c|c|c|c|}
\hline \begin{tabular}{|ll} 
& Semester \\
\end{tabular} & 1 & 2 & 3 & 4 & 5 & 6 & \begin{tabular}{|c|} 
Whole \\
Programme
\end{tabular} & Total \\
\hline NA & $\begin{array}{c}48 \\
(52.7 \%)\end{array}$ & $\begin{array}{c}14 \\
(15.4 \%)\end{array}$ & $\begin{array}{c}0 \\
(0 \%)\end{array}$ & $\begin{array}{c}2 \\
(2.2 \%)\end{array}$ & $\begin{array}{c}2 \\
(2.2 \%)\end{array}$ & $\begin{array}{c}8 \\
(8.8 \%)\end{array}$ & \begin{tabular}{|c|}
0 \\
$(0 \%)$
\end{tabular} & $\begin{array}{c}74 \\
(11.6 \%) \\
\end{array}$ \\
\hline Foundation & $\begin{array}{c}19 \\
(20.9 \%)\end{array}$ & $\begin{array}{c}29 \\
(31.9 \%) \\
\end{array}$ & $\begin{array}{c}20 \\
(22.0 \%) \\
\end{array}$ & $\begin{array}{c}10 \\
(11.0 \%) \\
\end{array}$ & $\begin{array}{c}7 \\
(7.7 \%) \\
\end{array}$ & $\begin{array}{c}0 \\
(0 \%)\end{array}$ & $\begin{array}{c}1 \\
(1.1 \%)\end{array}$ & $\begin{array}{c}86 \\
(13.5 \%)\end{array}$ \\
\hline Applied & $\begin{array}{c}16 \\
(17.6 \%) \\
\end{array}$ & $\begin{array}{c}21 \\
(23.1 \%) \\
\end{array}$ & $\begin{array}{c}13 \\
(14.3 \%) \\
\end{array}$ & \begin{tabular}{|c|}
19 \\
$(20.9 \%)$ \\
\end{tabular} & $\begin{array}{c}20 \\
(22.0 \%) \\
\end{array}$ & \begin{tabular}{|c|}
13 \\
$(14.3 \%)$ \\
\end{tabular} & $\begin{array}{c}12 \\
(13.2 \%) \\
\end{array}$ & $\begin{array}{c}114 \\
(17.9 \%) \\
\end{array}$ \\
\hline Graduate & $\begin{array}{c}8 \\
(8.8 \%) \\
\end{array}$ & $\begin{array}{c}27 \\
(29.7 \%) \\
\end{array}$ & \begin{tabular}{|c|}
58 \\
$(63.7 \%)$ \\
\end{tabular} & \begin{tabular}{|c|}
60 \\
$(65.9 \%)$ \\
\end{tabular} & $\begin{array}{c}62 \\
(68.1 \%) \\
\end{array}$ & \begin{tabular}{|c|}
70 \\
$(76.9 \%)$ \\
\end{tabular} & $\begin{array}{c}78 \\
(85.7 \%)\end{array}$ & $\begin{array}{c}363 \\
(57.0 \%) \\
\end{array}$ \\
\hline Total & $\begin{array}{c}91 \\
(100 \%)\end{array}$ & $\begin{array}{c}91 \\
(100 \%)\end{array}$ & $\begin{array}{c}91 \\
(100 \%)\end{array}$ & $\begin{array}{c}91 \\
(100 \%)\end{array}$ & $\begin{array}{c}91 \\
(100 \%) \\
\end{array}$ & $\begin{array}{c}91 \\
(100 \%) \\
\end{array}$ & $\begin{array}{c}91 \\
(100 \%)\end{array}$ & $\begin{array}{c}637 \\
(100 \%) \\
\end{array}$ \\
\hline
\end{tabular}

Table 4. Relationship between expected levels of competence development and semesters, based on student data

\begin{tabular}{|c|c|c|c|c|c|c|c|c|}
\hline Semester & $\mathbf{1}$ & $\mathbf{2}$ & $\mathbf{3}$ & $\mathbf{4}$ & $\mathbf{5}$ & $\mathbf{6}$ & $\begin{array}{c}\text { Whole } \\
\text { Programme }\end{array}$ & Total \\
\hline NA & 74 & 55 & 36 & 22 & 8 & 4 & 4 & 203 \\
& $(81.3 \%)$ & $(60.4 \%)$ & $(39.6 \%)$ & $(24.2 \%)$ & $(8.8 \%)$ & $(4.4 \%)$ & $(4.4 \%)$ & $(31.9 \%)$ \\
\hline Foundation & 15 & 32 & 37 & 33 & 28 & 22 & 22 & 189 \\
& $(16.5 \%)$ & $(35.2 \%)$ & $(40.7 \%)$ & $(36.3 \%)$ & $(30.8 \%)$ & $(24.2 \%)$ & $(24.2 \%)$ & $(29.7 \%)$ \\
\hline Applied & 2 & 4 & 17 & 35 & 42 & 33 & 33 & 166 \\
& $(2.2 \%)$ & $(4.4 \%)$ & $(18.7 \%)$ & $(38.5 \%)$ & $(46.2 \%)$ & $(36.3 \%)$ & $(36.3 \%)$ & $(26.1 \%)$ \\
\hline Graduate & 0 & 0 & 1 & 1 & 13 & 32 & 32 & 79 \\
& $(0 \%)$ & $(0 \%)$ & $(1.1 \%)$ & $(1.1 \%)$ & $(14.3 \%)$ & $(35.2 \%)$ & $(35.2 \%)$ & $(12.4 \%)$ \\
\hline Total & 91 & 91 & 91 & 91 & 91 & 91 & 91 & 637 \\
& $(100 \%)$ & $(100 \%)$ & $(100 \%)$ & $(100 \%)$ & $(100 \%)$ & $(100 \%)$ & $(100 \%)$ & $(100 \%)$ \\
\hline
\end{tabular}

In Tables 3 and 4, two clear trends are illustrated: the proportion of 'not applicable' competences decreased while graduate level competence development increased across semesters. The major difference was the pace of change. The changes noted in the staff 
findings (Table 3) occurred mainly in the first half of the programme (first three semesters) while the student data indicates a tendency to span over the whole programme, as shown in Table 4.

Table 5. Relationship between expected levels of competence development and years, based on staff data

\begin{tabular}{|c|c|c|c|c|c|}
\hline Level Year & $\mathbf{1}$ & $\mathbf{2}$ & $\mathbf{3}$ & $\begin{array}{c}\text { Whole } \\
\text { Programme }\end{array}$ & Total \\
\hline NA & 4 & 0 & 5 & 0 & 9 \\
& $(4.4 \%)$ & $(0 \%)$ & $(5.5 \%)$ & $(0 \%)$ & $(2.5 \%)$ \\
\hline Foundation & 32 & 10 & 1 & 1 & 44 \\
& $(35.2 \%)$ & $(11.0 \%)$ & $(1.1 \%)$ & $(1.1 \%)$ & $(12.1 \%)$ \\
\hline Applied & 20 & 19 & 13 & 12 & 64 \\
& $(22.0 \%)$ & $(20.9 \%)$ & $(14.3 \%)$ & $(13.2 \%)$ & $(17.6 \%)$ \\
\hline Graduate & 35 & 62 & 72 & 78 & 247 \\
& $(38.5 \%)$ & $(68.1 \%)$ & $(79.1 \%)$ & $(85.7 \%)$ & $(67.9 \%)$ \\
\hline \multirow{2}{*}{ Total } & 91 & 91 & 91 & 91 & 364 \\
& $(100 \%)$ & $(100 \%)$ & $(100 \%)$ & $(100 \%)$ & $(100 \%)$ \\
\hline F(Pearson chi-square test, p=0.00)
\end{tabular}

Table 6. Relationship between expected levels of competence development and years, based on student data

\begin{tabular}{|c|c|c|c|c|c|}
\hline Level & $\mathbf{1}$ & $\mathbf{2}$ & $\mathbf{3}$ & $\begin{array}{c}\text { Whole } \\
\text { Programme }\end{array}$ & Total \\
\hline NA & 48 & 10 & 4 & 4 & 66 \\
& $(52.7 \%)$ & $(11.0 \%)$ & $(4.4 \%)$ & $(4.4 \%)$ & $(18.1 \%)$ \\
\hline Foundation & 39 & 28 & 22 & 22 & 111 \\
& $(42.9 \%)$ & $(30.8 \%)$ & $(24.2 \%)$ & $(24.2 \%)$ & $(30.5 \%)$ \\
\hline Applied & 4 & 46 & 33 & 33 & 116 \\
& $(4.4 \%)$ & $(50.5 \%)$ & $(36.3 \%)$ & $(36.3 \%)$ & $(31.9 \%)$ \\
\hline Graduate & 0 & 7 & 32 & 32 & 71 \\
& $(0 \%)$ & $(7.7 \%)$ & $(35.2 \%)$ & $(35.2 \%)$ & $(19.5 \%)$ \\
\hline Total & 91 & 91 & 91 & 91 & 364 \\
& $(100 \%)$ & $(100 \%)$ & $(100 \%)$ & $(100 \%)$ & $(100 \%)$ \\
\hline
\end{tabular}

In Table 5, the 'not applicable' competence was around zero across years. The proportion of foundation and applied competence development decreased in contrast to the increase of graduate development across time. In Table 6, both the 'not applicable' and foundation level developments showed decreasing trends, while graduate development increased across the columns. Again, rapid changes were noted in the first half of the programme (between first and second years) based on the staff findings (Table 5), while these spanned over the three years according to the student data, Table 6.

\section{Overseas Questionnaire}

All the universities who responded require advanced level (A-level) or an equivalent level, such as Senior Secondary Certificate of Education (SSCE), as the primary entry 
requirement for the Bachelor courses in diagnostic radiography. Ninety percent (9 out of 10 ) offer a three year programme with only one (10\%) offering a four year programme.

All of the respondents stated that there are specified academic and / or clinical objectives in place for each year within the programme. Ninety percent of respondents indicated that the overall specified academic objectives for each year were the summated learning objectives for individual subjects in a particular year. The remaining respondent (10\%) stated that knowledge, practical, communication and interpersonal skills were the overall specified academic objectives for each year. For the overall clinical objectives of each year, twenty percent of respondents indicated that there were pre-determined, overall specified clinical objectives for each year, as derived from the National Benchmark Statements of Competency, such as Standards of Proficiency - Radiographers of United Kingdom ${ }^{16}$ and Competency Based Standards for the Accredited Practitioner of Australia. ${ }^{17}$ No such special arrangement was noted for the rest of the respondents (80\%).

The range of assessment tools used in overseas programmes to ensure that students can meet the academic and clinical objectives of each year is summarized in Table 7.

Table 7. Range of academic and clinical assessments

\begin{tabular}{|c|c|c|c|c|c|}
\hline \multirow{11}{*}{ 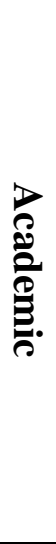 } & Type & Percentage & \multirow{9}{*}{ } & $\begin{array}{c}\text { Type } \\
\end{array}$ & Percentage \\
\hline & Written Examination & $100 \%$ & & Clinical Assessment & $77.8 \%$ \\
\hline & Written Assignment & $100 \%$ & & Direct Observation & $66.7 \%$ \\
\hline & Oral Presentation & $77.8 \%$ & & Reflective Writing & $55.6 \%$ \\
\hline & Practical Assessment & $55.6 \%$ & & Case Studies & $44.4 \%$ \\
\hline & OSCE & $22.2 \%$ & & Oral Examination & $44.4 \%$ \\
\hline & Case Studies & $22.2 \%$ & & Portfolio & $44.4 \%$ \\
\hline & Film Evaluation & $22.2 \%$ & & OSCE & $33.3 \%$ \\
\hline & Reflective Writing & $22.2 \%$ & & Self Evaluation & $11.1 \%$ \\
\hline & Oral Examination & $11.1 \%$ & & & \\
\hline & Portfolio & $11.1 \%$ & & & \\
\hline
\end{tabular}

For the assurance of integration of theory and practice, eight out of ten (80\%) institutions claimed that there is an arrangement for the assurance. Among these respondents, the arrangements referred to either the clinical (six out of eight, 75\%) or academic (two out of eight, 25\%) assessment strategies as noted above.

\section{Discussion}

\section{Stages of Progress}

Stages of progress refer to the periods of time for students to develop competences from a lower to a higher level. Hence, higher level development should increase from the beginning to the end of the programme, implying that no development should decline parallel to this, as characterised in the four cross-tabulations. However, it seems to be 
more appropriate to use years, rather than semesters, as the definite periods of time for students to complete competence progress. Although a decrease of 'not applicable' and an increase of 'graduate level' competences development across semesters were noted in Tables 3 and 4, other decreasing trends of lower level developments, such as decreases in foundation and applied developments across years, were noted in Tables 5 and 6 . This suggests that using years as the stages of progress should provide more adequate time for progressive development of competences of students. Hence, this should facilitate them in taking note of, and supporting, their individual development.

Indeed, the appropriateness of the use of years as the stages of progress correlates with the programme design as noted in the degree programme documentation. There are three stages within the programme. The first stage encompasses the first and second semesters, focusing on students' foundation development. The second stage includes the third and fourth semesters and mainly relates to applied knowledge development, while achievement of graduate capability is the emphasis of the third stage. ${ }^{18}$ Hence, this implies that the educational validity of the programme and the feasibility for students to develop their competences, using the stages of progress, can be determined.

\section{Standards of Progress}

Discrepancies were noted between staff and student findings in terms of the pace of development expected. It seems that staff expected students to develop to a greater extent in the first half of the study. On the other hand, students' own expectations were more on a step by step basis throughout the programme, which aligns more with the aim of this study. According to the programme's Programme Information document, ${ }^{18}$ the proportion of foundation subjects is greatest in the first year, while applied subjects provide the largest proportion in the second year and professional (graduate) subjects are the majority in the third year. In Table 6, the first two characteristics were noted in the student findings, that is the greatest proportions among the three levels in the first and second years were foundation and applied respectively. For the third year, graduate level development was only the second largest (35.2\%) with applied development being greater (36.3\%). In contrast, the staff findings matched the third characteristic noted in the programme design, with graduate development in the third year being the greatest (Table 5). These two expectations make sense at different stages.

A decision was taken to combine the two sets of standards of progress for each year, as well as for the whole programme, as derived from the staff and student data, as shown in Table 8.

Table 8. A snapshot of the standards of progress

\section{Social responsibilities and ethical practice}

\begin{tabular}{|c|c|c|c|c|}
\hline \multirow[t]{2}{*}{ Ensures at all times radiographers rights: } & \multicolumn{4}{|c|}{$\begin{array}{l}\text { Year (Roman) / } \\
\text { Whole Programme (P) }\end{array}$} \\
\hline & $\mathbf{I}$ & II & III & $\mathbf{P}$ \\
\hline Can say 'no' to inappropriate requests & $1-2$ & $2-3$ & $2-3$ & $2-3$ \\
\hline 2. $\quad$ Can explain reasons for decision & $1-2$ & $2-3$ & $2-3$ & $2-3$ \\
\hline 3. $\quad$ Can discuss pros and cons of disputed situations & $1-3$ & $2-3$ & $2-3$ & $2-3$ \\
\hline
\end{tabular}


Each competence statement within the standards of progress would be a range of criteria for each year, as shown in Table 8. This incorporates the expectations of both staff and students, with the lower limit reflecting the student expectations while the upper limit represents those of the staff. This decision was taken based on two considerations. If only the staff expectations are used, it could impose an unrealistically high expectation on students in general. In contrast, adoption of only the students' expectations would convey the message that competence attainment aims at ensuring individuals meet the threshold standards. However, when combining these two, the students would be clear that they must meet the lower limit of the range, that is acceptable progress of competence development, and they are encouraged to attain higher levels reaching towards the upper limit. According to the competence literature, adoption of the lowest common requirements as the competence standards was the main characteristic of behavioural competence which is criticized as a conservative approach. ${ }^{13,19,20}$ In contrast, holistic competence is seen as a concept which is a dynamic, constantly changing approach, bringing together complex combinations of knowledge, attitudes, values and skills with intelligent performance in specific situations. ${ }^{13,20}$ It is intended that the incorporation of the staff's higher expectations into the standards will acknowledge any intelligent performance of students. This encourages their attainment of holistic competence rather than behavioural competence. This arrangement also aligns with the concept of competence development not being an 'all or none' process but rather a continuum of development from novice to expert, so as to facilitate progress. ${ }^{9,12}$

It seems that the idea of using the student expectations as the baseline requirements has a pitfall in that four out of ninety-one (4.4\%) of 'not applicable' competences were noted in the whole programme column of Table 6. This may go against the aim of ensuring students' ability to meet all graduating professional competences at the end of the programme. However, when comparing the standards with the expectations of clinical radiographers, obtained from the Applied Learning Project, as a means of verification, such competences are not required for the graduate radiographer post but only expected at a more senior rank. This indicates the graduating professional competences are prospective and demonstrates the feasibility of the arrangement to use the student expectations as the baseline requirements.

\section{Review of the Soundness of Current Assessment}

From the staff findings, each year incorporates competence statements with psychomotor, cognitive and affective development and the proportions of each increase with time. There should be assessment instruments which can gauge these three domains each year and ideally, provide a wider base of evidence; for example, different assessment tools should be available especially in the senior year of study. ${ }^{20}$ The radiography programme includes thirteen forms of assessment. All of these can be considered as assessment tools for holistic competence. These include practical assessments and progress reports (direct observation), OSCEs, film evaluations and clinical assessments (in-training examinations), reflective writing (self evaluation), oral assessments, presentations and tutorial assessments (oral examinations), laboratory reports, written assignments and 
examinations (written assessments) and case study assignments (case-based learning). In the first year, there are only eleven forms of assessment, but this gradually increases up to thirteen by the third year, which is seen as matching the requirements noted above. ${ }^{13,18,21-}$ 26

\section{Framework Development}

Assessment of holistic competence is the most complex and difficult issue among the three basic approaches to competence, that is generic ${ }^{27-29}$, behavioural ${ }^{1-3,19,30,31}$ and holistic competence. This requires a multi-dimensional approach and any isolated instrument would not be adequate to gauge the overall competence. ${ }^{8,13,20,22}$ This strategy was in place in the programme, so as to ensure reliability and validity of the overall competence assessment. However, its time and resource effectiveness have still not been addressed. It is a fact that the multi-assessment approach is resource-demanding for ensuring individuals' competences. In order to justify the time spent and resources used, ways should be sought to maximize the outcomes. It is suggested that a portfolio model would provide the credibility to integrate all of the competence assessment tools, thus forming a holistic framework to gauge competence to a more manageable level, and this may be one way to address this issue. ${ }^{13}$

Portfolios are often labeled as an alternative means of assessment. They are capable of measuring complex intellectual capabilities such as competence. ${ }^{32-34}$ Since the portfolio is used to capture evidence of individuals' experiences in different forms, as a record to document development, it would be feasible to collect all assessment outcomes as evidence for portfolio building. It is suggested that a portfolio is an effective and efficient way to measure and record students' personal achievements and professional accomplishments in terms of occupational standards and competences. Through critical reflection of learning experiences, individual, separate evidence of professional and competence development, such as outcomes of multi-dimensional assessment strategies, are integrated and organized into a meaningful sense. It becomes a simple, clear and manageable display of attainments which are useful to stakeholders and students. ${ }^{13,35}$ Other capabilities noted in the portfolio pedagogy include promotion of reflective learning, ${ }^{13,34,36-43}$ mapping of students' career pathways, ${ }^{35,44}$ development of personal and professional attributes and various skills, ${ }^{32,35,37,38,41,43,45,46}$ assurance of education quality, ${ }^{34,35,39,45-47}$ and improvement of teacher-student relationships. ${ }^{34-37,41,45-48}$ To maximize the benefits of the portfolio as a simple, clear and manageable strategy, an electronic portfolio is suggested as the ultimate solution. The electronic portfolio has emerged over the past twenty-five years in education disciplines to promote collaborative learning. Recently, it has been identified as a solution to resource-demand problems associated with portfolio practice, such as time-consumption, storage and management. ${ }^{49}$

The framework developed in this study is based on the portfolio pedagogy which will operate initially as a voluntary activity. Those participating will be students wanting to receive increased support for their professional development, including progress towards, and ability to meet, graduating professional competences. The required standards of progress will be provided for them in advance at corresponding stages, following a 
reflection workshop on how to collect and select relevant materials, such as evidence from assessment instruments for the portfolio. They will be prepared in writing reflective notes that can link up the individual evidence so as to better illustrate the level of competence attainment relevant to the standard (the portfolio ties up the evidence from multi-dimensional assessment strategies). Throughout the academic year, a facilitator will be available to provide additional support and guidance to participants, such as assisting them to realize their development. Evaluation of the portfolio will be conducted by reading the reflective writing and the links to corresponding individual assessment evidence by faculty, to provide ratings of attainment of each competence statement noted. Feedback sessions will be conducted on an individual basis with participants to identify progress as well as possible areas for improvement in their competence development. Through this process, it should also be possible to obtain in-depth evidence of student learning and development to support participants and provide a means of evaluation of the programme. This practice will be repeated throughout the period of the participants' study as a means of monitoring their progress towards, and ability to meet graduating professional competences. Eventually, this framework concept will be transformed into an enterprise-level database portfolio system to address the resource-demand problems of the traditional portfolio practice due to its enormous capability of data storage and management. $^{49}$

\section{Further Study}

Another function of the electronic portfolio framework (system) would be the facilitation of professional development and evidence of life long learning of clinical radiographers by capturing, for example, their workplace outcomes, such as medical images produced. Therefore, connection and communication will be established between the electronic portfolio system and the Picture Archiving and Communication System (PACS). Integration of heterogeneous healthcare information systems is the trend in health care so as to leverage the benefits brought about by PACS, such as the wealth of data readily available for better health care delivery, research and education. However, the original mission of PACS relates primarily to clinical services. Hence, the medical imaging informatics infrastructure (MIII) which provides applications such as 3-D rendering and computer-aided detection (CAD) as a decision support tool has emerged. Other PACS application servers for medical specialties such as the radiation therapy (RT) server and the image-assisted surgery system (IASS) server have been developed to extend its considerable potential. The development of PACS as an educational tool also is another extension of utilization, including PACS simulator and digital teaching file development. Once established, a longer term aim is for the development of a digital teaching file for reporting continuing professional development (CPD), ${ }^{50}$ and the portfolio as a studentcentred learning pedagogy is an appropriate means to facilitate such development. ${ }^{13}$ Therefore, the extension of the electronic portfolio system as a PACS application server (the electronic portfolio system server connecting to the PACS) integrates the advantages of both PACS as a valuable resource of medical images and other related data, and the portfolio as an appropriate method to facilitate CPD. Although it may appear that connection between an electronic portfolio system and PACS may induce risk to patient privacy, implementation of security measures within the system, such as user 
authentication and auto-anonymization of images, safeguard the patient confidentiality and prevent abuse by users. The system ensures that users will only be able to retrieve images which have personal identifiers removed, for example.

\section{Advancements of the Framework in Comparison with Other Assessment Practices}

The portfolio framework concept developed in this study as noted in the Framework Development section provides a clear pathway for students to progress and eventually attain the radiography graduating competences as an alignment of adult learning theory, ${ }^{51}$ in contrast to other practices, including portfolios which only support their progress towards meeting specific learning objectives, and which do not support their preparation for the attainment of, for example, the National Benchmark Statement of Competency. ${ }^{16,17}$ This is an integrative framework rather than one supporting individual applications in either academic or clinical subjects, as noted in the findings of the overseas questionnaire. This integrative approach supports faculty members to monitor and provide feedback to students using a holistic approach and also facilitates students to integrate theory and practice during the portfolio building process. Furthermore, the standards of progress established are not in an 'all or none' sense, but rather incorporates the philosophies of the novice to expert continuum ${ }^{12}$ and attainment of holistic competences, to acknowledge a range of student abilities, including intelligent performance beyond the benchmark level, in meeting the requirements of professional competence standards.

\section{Study Limitations}

There are two limitations of this study. The first relates to the development of stages and standards of progress, which have only been based on one set of findings from staff and students. Further validation is required through repeated applications of questionnaires and feedback from the participants of the portfolio framework. The relatively low response rate of the overseas questionnaire is the second weakness. However, it is suggested that mailed and web-based questionnaires usually yield $50 \%$ or lower response rates, ${ }^{14}$ and the usual response rate of a mailed survey should be $25 \% .{ }^{52}$ Mailed questionnaires achieved a $25 \%$ response rate in the experimental group for which respondents received incentives for completion of questionnaires. By contrast, only an $18 \%$ response rate was yielded in the control group. ${ }^{53}$ Hence, the response rate obtained in this study should be adequate.

\section{Conclusion and Planned Progressions}

The first part of this study established the stages at which required student graduating competences should be attained. It was established that years of study rather than semester periods were appropriate to allow students to meet the standards. A range of abilities is also noted at different stages to allow for students to meet the overall competence recognising the fact that among a class group they will not progress at the same rate, and will not, in terms of clinical experience, have the same experiences at the same time. This also informs the requirements of assessment strategies for diagnosis of 
students' development as a basis of a review of soundness of the current assessment processes. Although the multi-dimensional assessment approach in place in the programme should be adequate to gauge the students' progress, time and resource effectiveness has not yet been addressed. The portfolio was identified as the pedagogy capable of integrating all the competence assessment tools through reflective writing, so as to link individual outcomes into a whole, and to form a holistic framework, that is the method of monitoring radiography students' progress towards, and ability to meet graduating professional competences. The portfolio framework will initially run as a voluntary activity without any incentive and standards of progress corresponding to the students' stages will be delivered to participants in advance. In turn, participants are required to select materials and reflect on these, as evidence of their development. Faculty members will be required to provide support and feedback to students and oversee the whole process so as to achieve the aim of this study.

In terms of the outcomes of this study, the framework will be transformed into an enterprise-level database portfolio system. Further validation of the portfolio framework concept will be conducted by putting the electronic system into practice with two cycles of operation, that is implementation of the electronic portfolio practice for two rounds. Findings will then be used to revise / modify / improve both the concept and system so as to establish a robust electronic portfolio. Extension of the electronic portfolio framework could include a means of facilitating continuing professional development (CPD) and evidence of life long learning of clinical radiographers by capturing, for example, their workplace outcomes, such as medical images produced. Therefore, communication between the electronic portfolio system and the PACS will incorporate security measures, such as user authentication and auto-anonymization of images, so as to safeguard patient confidentiality. If an electronic portfolio system with PACS connectivity is successful, the outcomes could be extended to monitor CPD of clinical radiographers. Since CPD is developing among all health professions, it could also be extended to other professional areas so as to provide evidence of practitioners' competences throughout their professional life.

\section{References}

1. Meerabeau E. Back to the bedpans: the debates over preregistration nursing education in England. Journal of Advanced Nursing 2001; 34(4): 427-35.

2. United Kingdom Central Council for Nursing, Midwifery and Health Visiting. Fitness for practice and purpose. London: United Kingdom Central Council for Nursing, Midwifery and Health Visiting; 2001.

3. United Kingdom Central Council for Nursing, Midwifery and Health Visiting. Fitness for practice. London: United Kingdom Central Council for Nursing, Midwifery and Health Visiting; 1999.

4. Pew Health Professions Commission. Recreating health professional practice for a new century: the fourth report of the Pew Health Professions Commission. San Francisco: University of California; 1998.

5. Storey L, Haigh C. Portfolios in professional practice. Nurse Education in Practice 2002; 2: 44-8. 
6. Fawcett TN. Teaching, assessing and evaluation for clinical competence. Journal of Advanced Nursing 2001; 33(3): 416.

7. McKinley RK, Fraser RC, Baker R. Model for directly assessing and improving clinical competence and performance in revalidation of clinicians. British Medical Journal 2001; 322(7288): 712-5.

8. Flanagan J, Baldwin S, Clarke D. Work-based learning as a means of developing and assessing nursing competence. Journal of Clinical Nursing 2000; 9(3): 360-8.

9. Williams PL, Berry JE. What is competence? A new model for diagnostic radiographers: part 1. Radiography 1999; 5: 221-35.

10. Williams PL, Berry JE. What is competence? A new model for diagnostic radiographers: part 2. Radiography 2000; 6: 35-42.

11. Biggs J. Enhancing teaching through constructive alignment. Higher Education 1996; 32: 347-64.

12. Benner P. From novice to expert: excellence and power in clinical nursing practice. California: Addison-Wesley Publishing Company; 1984.

13. McMullan M, Endacott R, Gray MA, Jasper M, Miller CML, Scholes J, Webb C. Portfolios and assessment of competence: a review of the literature. Journal of Advanced Nursing 2003; 41(3): 283-94.

14. Polit DF, Beck CT. Nursing research: principles and methods. 7th ed. Philadelphia: Lippincott Williams \& Wilkins; 2004.

15. Johnson B, Christensen L. Educational research: quantitative and qualitative approaches. Boston: Allyn and Bacon; 2000.

16. Health Professions Council. Standards of proficiency - radiographers. London: Health Professions Council; 2003.

17. Australian Institute of Radiography. Competency based standards for the accredited practitioner. Collingwood: Australian Institute of Radiography; 2005.

18. Department of Optometry and Radiography. Bachelor of science with honours in radiography (medical imaging / radiation therapy): programme information. Hong Kong: Department of Optometry and Radiography, The Hong Kong Polytechnic University; 2004.

19. Franklin K. National vocational qualifications, Scottish vocational qualifications and competence-based education and training: from de ville to beaumont. Journal of Vocational Education and Training 1997; 49(4): 511-30.

20. Gonczi A. Competency based assessment in the professions in Australia. Assessment in Education: Principles, Policy and Practice 1994; 1(1): 27-44.

21. Pasquina PF, Kelly S, Hawkins RE. Assessing clinical competence in physical medicine \& rehabilitation residency programs. American Journal of Physical Medicine \& Rehabilitation 2003; 82(6): 473-8.

22. Watson R, Stimpson A, Topping A, Porock D. Clinical competence assessment in nursing: a systematic review of the literature. Journal of Advanced Nursing 2002; 39(5): 421-31.

23. McKinley RK, Fraser RC, Baker R. Model for directly assessing and improving clinical competence and performance in revalidation of clinicians. British Medical Journal 2001; 322(7288): 712-5.

24. Flanagan J, Baldwin S, Clarke D. Work-based learning as a means of developing and assessing nursing competence. Journal of Clinical Nursing 2000; 9(3): 360-8. 
25. Sliwa JA, Kowalske KJ. Assessing resident clinical competence. American Journal of Physical Medicine \& Rehabilitation 2000; 79(5): 468-73.

26. Holmboe ES, Hawkins RE. Methods for evaluating the clinical competence of residents in internal medicine: a review. Annals of Internal Medicine 1998; 129(1): 42-8.

27. Barrett GV, Depinet RL. A reconsideration of testing for competence rather than for intelligence. American Psychologist 1991; 46(10): 1012-24.

28. Masterpasqua F. A competence paradigm for psychological practice. American Psychologist 1989; 44(11): 1366-71.

29. McClelland DC. Testing for competence rather than for "intelligence". American Psychologist 1973; 28: 1-14.

30. Odell A, Bonson B, Harmsworth A, Hill S, Jones C, Lake E, Leaver G. Competency in practice. Nursing Management 1996; 3(5): 19-21.

31. Ashworth P. Being competent and having 'competencies'. Journal of Further and Higher Education 1992; 16(3): 8-17.

32. Tiwari A, Tang C. From process to outcome: the effect of portfolio assessment on student learning. Nurse Education Today 2003; 23: 269-77.

33. Forker JE, McDonald ME. Methodologic trends in the healthcare professions: portfolio assessment. Nurse Educator 1996; 21(5): 9-10.

34. Gredler ME. Implications of portfolio assessment for program evaluation. Studies in Educational Evaluation 1995; 21: 431-7.

35. Ryan M, Carlton KH. Portfolio applications in a school of nursing. Nurse Educator 1997; 22(1): 35-9.

36. Karlowicz KA. The value of student portfolios to evaluate undergraduate nursing programs. Nurse Educator 2000; 25(2): 82-7.

37. Gordon J. Assessing students' personal and professional development using portfolios and interviews. Medical Education 2003; 37: 335-40.

38. Pitts J, Coles C, Thomas P. Enhancing reliability in portfolio assessment: “shaping” the portfolio. Medical Teacher 2001; 23(4): 351-6.

39. Lonka K, Slotte V, Halttunen M, Kurki T, Tiitinen A, Vaara L, Paavonen J. Portfolios as a learning tool in obstetrics and gynaecology undergraduate training. Medical Education 2001; 35: 1125-30.

40. Open University School of Health \& Social Welfare. Building portfolios. Nursing Management 2002; 9(1): 30-3.

41. Harris S, Dolan G, Fairbairn G. Reflecting on the use of student portfolios. Nurse Education Today 2001; 21: 278-86.

42. Gallagher P. An evaluation of a standards based portfolio. Nurse Education Today 2001; 21: 409-16.

43. Ball E, Daly WM, Carnwell R. The use of portfolios in the assessment of learning and competence. Nursing Standard 2000; 14(43): 35-7.

44. Weddle DO, Himburg SP, Collins N, Lewis R. The professional development portfolio process: setting goals for credentialing. Journal of the American Dietetic Association 2002; 102(10): 1439-44.

45. Alexander JG, Craft SW, Baldwin MS, Beers GW, McDaniel GS. The nursing portfolio: a reflection of a professional. The Journal of Continuing Education in Nursing 2002; 33(2): 55-9. 
46. Snadden D, Thomas ML. Portfolio learning in general practice vocational training - does it work? Medical Education 1998; 32: 401-6.

47. Barootchi N, Keshavarz MH. Assessment of achievement through portfolios and teacher-made tests. Educational Research 2002; 44(3): 279-88.

48. Ramey SL, Hay ML. Using electronic portfolios to measure student achievement and assess curricular integrity. Nurse Educator 2003; 28(1): 31-6.

49. Kimball M. Database e-portfolio systems: a critical appraisal. Computers and Composition 2005; 22(4): 434-58.

50. Huang HK. PACS and imaging informatics: basic principles and applications. $2^{\text {nd }}$ ed. New Jersey: John Wiley \& Sons, Inc.; 2004.

51. Knowles M. The adult learner: a neglected species. $4^{\text {th }}$ ed. Houston: Gulf Publishing Company; 1990.

52. Ray JJ, Still LV. Maximizing the response rate in surveys may be a mistake. Personality and Individual Differences 1987; 8(4): 571-3.

53. Angur MG, Nataraajan R. Do source of mailing and monetary incentives matter in international industrial mail surveys? Industrial Marketing Management 1995;

24(5): 351-7. 